\title{
Szu-chien Hsu, Kellee S. Tsai, and Chun-chih Chang, eds., Evolutionary Governance in China: State-Society Relations under Authoritarianism
}

\author{
(Cambridge, MA: Harvard University Asia Center, 2021), 396p. \$32.95 \\ paperback
}

\section{Vivienne Shue ${ }^{1}$}

Accepted: 7 April 2021 /Published online: 15 April 2021

(c) Journal of Chinese Political Science/Association of Chinese Political Studies 2021

This volume joins a swiftly advancing analytic turn within the literature on statesociety relations in contemporary China, adopting an evolutionary (or co-evolutionary) framework for theorizing the dynamics of change and longer-term trends in development. In the able hands of its three editors, this collection brings together no fewer than a dozen original contributions, most based on extensive field research carried out over several years.

The introduction, by Kellee Tsai, expertly reviews recent theoretical literature on state-society relations. The prolonged prominence of the "authoritarian resilience" paradigm generated a proliferation of studies classifying China as "authoritarian with adjectives," she writes, underscoring the value to be gained by moving on, now, to a more flexible, potentially open-ended evolutionary analytic framework; one "that traces the dynamics and outcomes of state-society engagements over time." (p.21) In Chapter 2, the volume's two other co-editors, provide a complementary tour d'horizon of pertinent empirical investigations, as reported by scholars between 2005 and 2015. Assembling a unique data base from research reports published in English over that period, Hsu and Chang deploy a quantitative analysis pointing to some broad hypotheses about strategies, processes, and outcomes achieved through societal actions undertaken with intent to change policy and/or garner greater power of participation in governance. They develop a $2 \times 2$ typology of state and societal strategies, each "ranging from hard to soft" (p. 45), and generate hypotheses about which combinations of strategies are more and less likely to result in positive changes to governance outcomes.

In a brief epilogue, interestingly framed in the context of the COVID-19 pandemic, Elizabeth Perry raises a caution - one many readers may share - about such

Vivienne Shue

vivienne.shue@sant.ox.ac.uk

1 University of Oxford, Oxford, UK 
an interactive-strategies-based approach. Fixing the analytic focus on strategic choice and interaction over time - as with all game-theoretic approaches (including "evolutionary game theory"), risks side-lining consideration of any deeper historic antecedents conditioning strategy selection. Perry's concern is with "losing sight" of the Leninist-revolutionary heritage that is "baked into the Chinese Communist Party's DNA" (p.393). We might, however, equally raise concern about losing sight of still earlier, imperial-bureaucratic, legacies and "stigmata" (p. 394) to be found, still, in contemporary patterns of Chinese governance.

The remaining chapters are all written by Chinese scholars based in East Asia, primarily in Taiwan. Cases are mostly drawn from the greater Beijing or Guangzhou/Pearl River Delta regions. They deal with a wide array of social governance arenas: public health/environment; domestic violence/women's rights; peri-urban land requisition; labor/management conflicts; homeowners' community concerns; and control over popular cultural and religious practices. Several encompass interactions with non-domestic economic and social actors, including foreign investors and international NGOs.

Among the most absorbing case accounts are two contrasting governance over religious practices - one classified as belonging to Chinese culture (Ming-chun $\mathrm{Ku}$ on Mazu Belief) and another as not belonging to Chinese culture (Ke-hsien Huang on Christian churches). Also richly revealing are those documenting unanticipated outcomes or unintended consequences of specific strategic choices (Christina Chen on the unforeseen effects of enacting progressive labor legislation; and Thung-Hong Lin on international capital flight and relocation of foreign investment following the Foxconn workers' suicide-protests of 2010). A chapter by Szu-chien Hsu and Muyi Chou advancing the concept of "cellularized" civil society and its contribution to authoritarian resilience likewise deserves careful study and future application.

All case chapters show signs of having been subject to rigorous editing, yielding consistently fine clarity in exposition, and accessible prose. This should make the volume very useful in teaching; as will the decision to publish in paperback. Strong and consistent editing has also, however, imparted a rather fixed, repetitive format for presenting research questions and findings. Main insights and conclusions are summarized at the beginning of each chapter, and again at the end, in very much the same terms. This serves, regrettably, to confine what might have been some intriguingly nuanced factual narratives to fairly cursory overviews, in several cases. Most chapters have also been constructed to present key developments in successive "phases" or "stages" of state/society interaction over time. In several chapters, this serves very nearly to reduce the fecund concept of "evolutionary governance" to one of "diachronic" process tracing. Future research framed along "evolutionary" lines may better aim for interpretations more dialectical, than merely diachronic.

Vivienne Shue FBA is Emeritus Professor of Contemporary China Studies at the University of Oxford, and a Fellow of St. Antony's College. 